\title{
The Influences of WTO Accession on China's State-Owned Enterprises
}

\author{
Shanshan Li, Ningxiang Xu \\ Management School, Jinan University, Guangzhou, China \\ Email: lishan7855@163.com
}

Received 30 March 2015; accepted 16 April 2015; published 20 April 2015

Copyright (C) 2015 by authors and Scientific Research Publishing Inc.

This work is licensed under the Creative Commons Attribution International License (CC BY). http://creativecommons.org/licenses/by/4.0/

\begin{abstract}
Up to the present, nearly fourteen years have passed since China's accession to WTO. Among the various impacts the accession may bring about, the one on State-owned Enterprises (SOEs) was most widely concerned due to their special characteristics and particular roles in Chinese economy, politics and society. This essay will briefly introduce the history of China's SOE reforms and then summarize previous research to demonstrate the expected influences of the accession. Then privatization and removal of protective government policies will be examined in detail, followed by an evaluation of the effect of privatization.
\end{abstract}

\section{Keywords}

WTO Accession, China's SOEs, Privatization, Protection Policies

\section{Introduction}

In 2001, China joined the World Trade Organization (WTO), which is of great significance to both China's economic and social developments. According to the WTO accession protocol, China was required to carry out a number of trade policy reforms, including tariff reduction, elimination of subsidies and opening up domestic markets, to conform to the WTO regulations and to promote an open economy. Among the various impacts the accession to WTO may bring about, the one on State-owned Enterprises (SOEs) was most widely concerned due to their special characteristics and particular roles in Chinese economy, politics and society. On one hand, China's SOEs were generally perceived as huge, inefficient and problematic to which drastic measures should be taken. On the other hand, SOEs played a critical role in leading the domestic market, dominating pivotal industries and absorbing labor force. Therefore, whether a change in their state-owned property is inevitable to achieve improvement is controversial and has received extensive debates.

Up to present, nearly fourteen years have passed since the accession. Although certain reforms, such as the Management Buy-Outs (MBO), were implemented during this period as a response to WTO rules, their effects 
remained medium. This essay will first briefly introduce the history of China's SOE reforms and then summarize previous research to demonstrate the expected influences of the accession. In the third part, two types of reforms, namely privatization and removal of protective government policies, will be examined in detail, followed by illustration of empirical examples. The third part will also evaluate the effect of privatization as a dominant approach in SOE reform.

\section{China's SOE Development and the WTO Accession}

Prior to the 1978 economic reform, China had adopted a central-planning economy in which political propaganda and ranking promotion rather than material rewards were designed to motivate workers. Moreover, the productions in SOEs were all decided centrally with costs covered and profits submitted. Since 1978, a series of market-oriented policies were put forward gradually aimed at injecting incentives for enhancing productivity and profitability of SOEs. In spite of some microeconomic managerial adjustments and limited autonomy introduced, SOEs still lacked essential attributes as a market entity and were inefficient. Later on, privatization took place in small to medium-sized SOEs. However, while significant transformation was experienced in the small SOE sector, the effect on mid to large SOEs remained negligible. Overall, the number of SOEs, along with their contribution to the total output and employment, has declined drastically throughout the reform process. Inconsistent with this phenomenon was the substantial proportion of domestic investment and savings shared by the SOEs. Moreover, government subsidies were always available to compensate for the losses incurred by the SOE sector, which further weakened the incentive for an efficiency growth. Also, due to an absence of personal stake by managers for inappropriate use of assets, an increase in management autonomy had exacerbated the problem of on-job-consumption and embezzlement. Meanwhile, the SOE not only had been granted an abnormally low price for rent and loans, but also enjoyed monopoly power in a number of markets which were blocked to the private sector. Worse still, all these favorable conditions did not prevent SOEs from running loss-making and generating huge non-performing loans. Therefore, it is argued that the highly inefficient SOEs were actually adding to the burden of China's economy and should be reformed fundamentally [1].

China's accession to WTO was somewhat viewed as a real momentum to the SOE reform process. According to the Agreement on Subsidies and Countervailing Measures (SCM) [2], China was required to terminate preferential government subsidies and bank supports to the SOE. Furthermore, some previously inaccessible markets, including the banking industry, had to be opened up to foreign companies. Therefore, domestic banks would become more profit-based and try to prevent non-performing loans by the SOE. Given the impending competition and legislative pressure, the accession to WTO was expected to be a channel both to regulate government behavior and to accelerate SOE reforms [1].

Based on Bajona and Chu's dynamic general equilibrium model, removals of minimum employment restriction and subsidies to capital would have significant influence on GDP, welfare and SOE output shares. Assuming a closed economy with fixed tariff to isolate the effects of SOE reforms, this model tested the data from 1978 to 2001 to infer a foresight of the tendency under WTO regulations. As a result, there tended to be strong negative correlation between the reduction of the minimum employment level and the SOE market shares. That is, as the labor restriction being released gradually, the SOE decreased in its contribution to the total output. In terms of the subsidies' effect, a reduction in subsidy would weaken the role of the SOE in traded sector while a small reduction tended to boost SOE shares in non-traded sector at first until the reduction became sufficiently large. The effect is represented in Figure 1.

This might be explained as the SOE were traditionally heavily subsidized and less productive than the private sector, especially in the traded sector. Therefore, a withdrawal of subsidy first drove a reallocation of resources from inefficient SOEs in traded sector to SOEs in non-traded sector. Yet the factor of efficiency and productivity tended to dominate in the long run so that the SOE declined relative to the private sector with further subsidy reduction. Also, there would be gains in both welfare and real GDP with the industry deregulation. Hence, it is most likely to experience a downsizing SOE sector after the WTO accession. In addition, numerous literatures also predicted an efficiency growth induced by the WTO accession in existing SOEs [3].

\section{Reforms and Related Arguments}

\subsection{Privatization}

Although the process of privatization was first introduced in China at the beginning of 1990s, it was expected to 
SOE share (non-traded sector)



Figure 1. The correlation between the reduction of the minimum employment level and the SOE market shares.

be further accelerated by the accession to the WTO [4]. In China, privatization was implemented mainly through three approaches, namely management buy-outs (MBO), share issue privatization (SIP), Joint Venture and reduction of state-owned shares. This section will focus on the impacts of MBO and briefly summarize the influences of other approaches.

To begin with, MBO can be defined as a form of acquisition of a firm by its existing managers, thus transfers the ownership of the firm from state-owned to private. As is widely noticed, the agency problem in SOEs is prevailing. Aimed at alleviating this problem, the MBO process combined the property ownership with the operation rights to exploit the potential in efficiency improvement. Based on organizational theories, motivation to managers is necessary in order to activate their initiatives. However, many short-term motivations, such as salary, bonus and welfare, only have a one-off effect and are considered unsustainable and expensive. Moreover, when a company enters into a stable phase with minor fluctuations in sales revenue, cash flow and stock price, using stock shares or options as an incentive to managerial commitment seems to have feeble effect. Also, due to a stable stock price, the value of the stock as debenture investment declines. Thus, those stocks are more likely to be sold by stock investors. It is under such a dilemma that MBO comes about as a solution to stimulate managers' involvement in reducing the cost because the potentially resulted profits would far exceed their annual salaries [5].

In terms of China's MBO course, the first case took place in the Stone Corporation in 1998. Previously, this company had a private collective ownership. Nevertheless, since 1990s, the vague property ownership had become a serious constraint to future development and had led to 3 major splits among the top hierarchy in the company. Furthermore, the absence of a clear ownership structure resulted in numerous problems, including an unclear business direction, an over-heated expansion, an inert organizational mechanism, a loss of human capital and a high operation cost. Ultimately, the Stone Corporation initiated an Employee Stock Ownership Plan (ESOP), ended up with more than 60\% shares in the hand of the 16 core executives. Also, through several issues of new shares, the existing unclearly defined assets were gradually diluted and distributed among share holders [6].

Afterwards, in 2001, GD Midea announced that its 724.303 billion shares were transferred from Shunde Midea Co., Ltd., a company mainly funded by the local government, to Shunde Meituo Investment Co., Ltd., a company established collectively by the Midea Group’ management and the labor union. Hence, the GD Midea Company had accomplished the MBO process with the management being the largest shareholder and possessing $22.19 \%$ of its total shares. Although most of the funds needed for the acquisition were gathered via a mortgage on the company's equity, the restructuring was quite successful and possibly contributed to the later exceptional performance of the company [7].

Since then, the MBO process was triggered in China. For example, China Comfort Travel (CCT), Shenzhen 
Fangda Group, Yutong Bus and GD Macro all had undergone MBOs in a typical way [5]. According to Gan et al, MBOs accounted for nearly half of the total privatization programs in China and had achieved most prominent progress in terms of business performance compared to other privatization approaches. However, the outcomes of those MBOs still varied from case to case. For instance, the Midea Company has implemented a number of internal reforms after its MBO process, including changing the top management and optimizing the organization structure. In 2002, the company divided its electrical household appliance division into four individual units, enlarging its original six divisions to nine. Moreover, the company has experienced a steady growth in its sales and profitability with an evident direction of developing its primary business. Whereas Shenzhen Fangda incurred a 0.58 Yuan loss per share in 2002 and a 0.031 Yuan loss per share in 2003 instead of an expected profit gain after its MBO procedure. On the other hand, some companies encountered intractable difficulties and interest conflicts in their attempts to implement the MBO. One unfortunate example would be the Jianlibao Company, whose development was even hindered by its miserable MBO experience [7]. Consequently, the conflict between its manager and the local government was not resolved and the company was acquired by the Uni-President Enterprises some time ago.

Meanwhile, problems and disputes towards China's MBO process were also prevailing. Firstly, due to the relatively undeveloped financial market in China, the financing channels for gathering the essential funds were narrow and highly restricted. Obviously, while China tried to connect its economy to the international market particularly through the WTO accession, its legislative and financial sectors lagged behind to fit for the changing situation. Various ways of typical international fund-raising, such as credit loans, supplier credit finance and convertible subordinate note, were not available in China's financial market [8]. The imbalance between the demand and the supply of capital induced managers to use bank loans as an alternative approach. Indeed, this method involved substantial legal and financial risk. To illustrate, according to the 43th provision of Law on Commercial Banks, commercial banks were prohibited from investing in non-banking financial institutions or enterprises. Also, based on Lending General Provisions, debtors were not allowed to use the loans to engage in equity interest investment. Yet in reality, managers, such as the ones of the Midea, sometimes used the equities of the targeted company as collateral to get bank loans. Furthermore, while it was the managers who were expected to assume the risk of the buyout, the risk was often transferred to other shareholders and creditors as the average amount of shares acquired by managers was only $25 \%$ in China [8].

Secondly, the price of the shares acquired by managers were not set by the market mechanism, but rather decided internally through agreements. Hence, the price was usually unfairly low, which was somewhat considered plundering of state-owned assets by management. For example, in Shenzhen Fangda Group's MBO, the equity transfer price was 3.28 Yuan per share in the first buyout, 3.08 Yuan per share in the second one, both lower than the net asset value per share of 3.45 Yuan. And Mingxiong Jian, chairman of the board, had experienced a dramatic expansion in terms of his private property up to 1.6 billion RMB via these MBOs [7]. Moreover, this factor was also strongly cited by Lang Xianping to argue against the extensive implementation of MBO. Instead, Lang claimed that SOEs could achieve efficiency if employ market managers while MBO might indeed contribute to considerable hidden social cost [9]. Worse still, the prevalence of MBOs might result in a prospect among managers of the remaining firms that they were also going to take over the company through MBO. Consequently, managers might behave in their own interests to deliberately lower the value of their companies through certain maneuver. The cheaper the enterprise, the more likely the managers could afford it. Undoubtedly, the interests of small other shareholders were seriously prejudiced under such a circumstance [10].

In addition, partially due to an undeveloped information disclosure system, transparency of the buyout process was quite low. Specifically, since sources of required funds were usually kept from outsiders, along with related party transactions and internal transactions, supervision over state-owned assets became rather difficult and infeasible. More importantly, to earn a short-term profit, some managers even sold their shares at the market price after MBO at the expense of a loss of state-owned assets [5]. Besides, excessive government interventions sometimes distorted the function of market in guiding companies to adopt MBO. As a result, some enterprises faced enormous difficulties in obtaining funds whereas others did not. This impeded the healthy development of a fair financing market [8].

On the other hand, it was argued that cross regional privatization in China had been completed with varied degrees. Privatization was accomplished more thoroughly and control rights had been transferred from government to enterprises more completely in cities than in rural areas [5]. Figure 2 provides an overview of the distribution of privatization. 


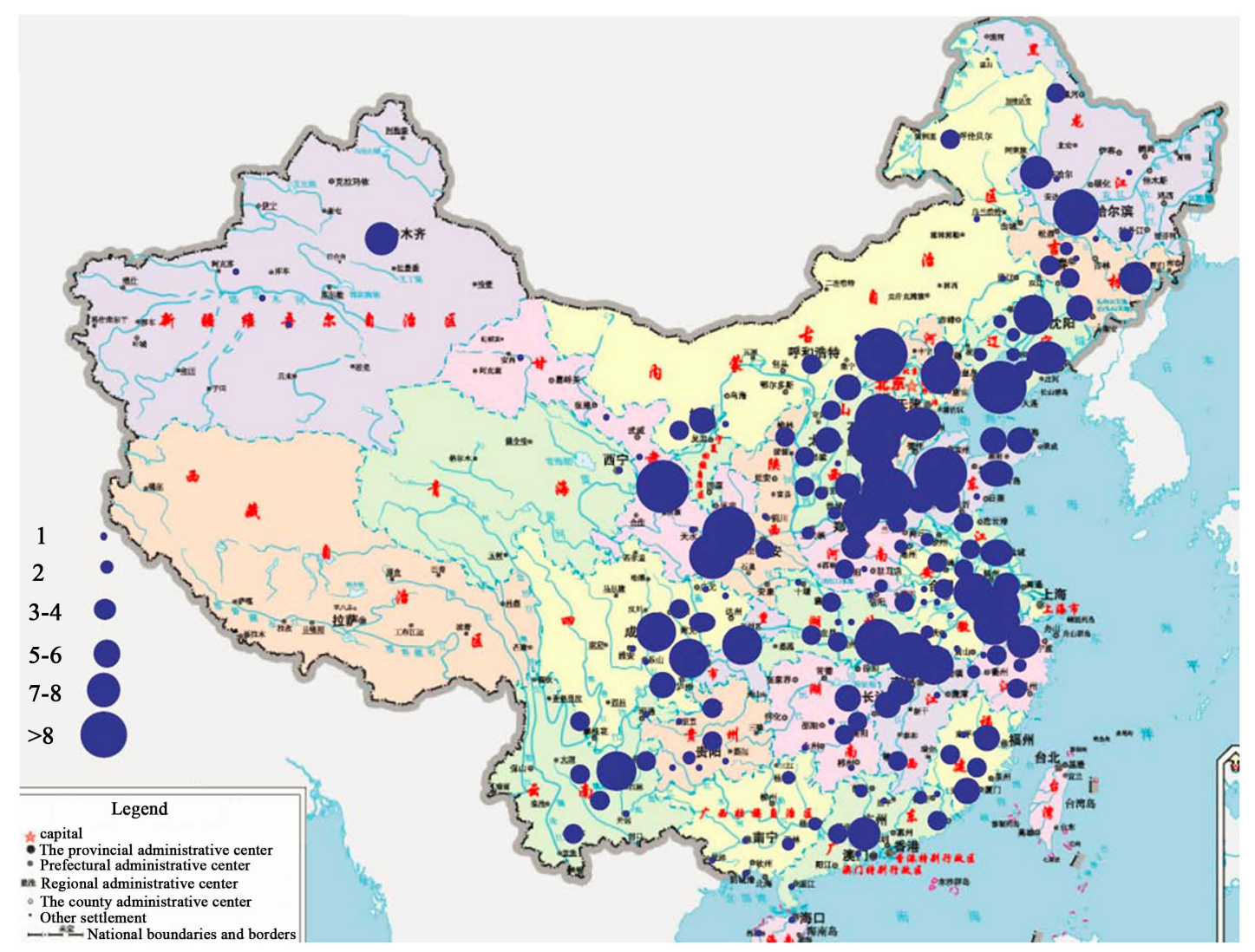

Figure 2. An overview of the distribution of privatization.

This finding was probably associated with the fact that the influence of the WTO accession was more profound in cities than in countries as the former was exposed to the open economy earlier and on a broader scale. However, studies by Chan and Unger suggested that privatization in fact had only mild influence on the internal governance, labor relations and employee benefits in small scale SOEs [11]. Many of them had largely retained attributes of a state enterprise after being privatized. Based on a long-term survey on a local distillery, except for a reduction in the size of employment and a change in wage system, the firm inherited the majority aspects from the previous practices. Detailed speaking, the distillery continued to adopt an organization-oriented model by promoting relatively egalitarian payment with minimized gaps among members. Gifts, subsidies and other benefits to employees and retirees were still provided. Besides, the staff and workers representative congress continued to exist and the manager intended to maintain an "enterprise family" culture within the firm. This finding can be explained that managers had successfully taken some strategies to get through the transition period and accommodate employees to a new environment. In spite of the positive cases, privatization had contributed to a capitalism model that managers tended to exploit the benefits of employees and behaved towards self-enrichment [12].

\subsection{Evaluation of the Privatization Result}

Generally, privatization of the SOEs is viewed as a crucial part in the economic transition from a central-planning economy to a market economy. Compared with Central-Eastern economies and Russia, the privatization process in China had been delayed too long due to a reluctant government inclination [13]. It started almost 20 years after the beginning of China's economic reform. Thus, it might be interpreted as an outcome under the pressure of the WTO accession. In terms of the post-privatization performance, the survey conducted by Gan et al. on a nationwide scale of 3065 firms with above 5 million RMB sales has presented a relative comprehensive picture. The findings have revealed strong evidence that private ownership was concentrated and corporate governance was improved after privatization. Also, less involvement by government in firms’ operations and deci- 
sion-making was observed. Furthermore, firms' budget constraints have become much more tightened. Also, the findings suggest non-SIP approaches, especially MBO, as most effective in introducing efficiency gains as well as transparency measures to firms' business practices.

Based on this research, there was a prominent enhancement regarding firm performance. Specifically, the profits over assets ratio and the profits over number of employees ratio had increased by $10 \%$ and $5 \%$ respectively when comparing the pre and post stages of privatization. Nevertheless, whereas privatization was examined to have positive effect on performance, 2 primary factors could probably exaggerate the magnitude of the real impact of privatization. One is that governments were more likely to privatize firms with greater potential in profit-making. The other is that managers might deliberately drive down the stock price by manipulation prior to the privatization. Thus, the seemingly profit growth afterwards could be a simply returning-to-normal effect. Furthermore, Tong reported that it was the reinforcing competition, the increasingly concentrated FDI and the hardening SOEs' budget constraints that play an instrumental role in leading to the emergence of privatization [14]. All these factors were considered results of the WTO accession. When viewing from a worldwide perspective, privatization was a core tool accepted by more than 100 countries for economic transformation from state to market. Also, numerous studies had tested its influence over companies' performance employing different methodologies. And almost all of them had recognized superior performances in privatized firms relative to un-privatized ones [15].

\subsection{Elimination of Protection Policies}

As mentioned above, the WTO accession would induce a reduction in both direct and capital subsidies as well as a soft budget constraint to SOEs, which created an opportunity for SOEs to become more efficient. In the early stage of the accession, Chinese government had place a priority on removing excessive SOE subsidies to standardize the market [16]. Yet in reality, government subsidies were still available to a number of large SOEs and large listed companies at present. Many of those listed companies were transformed from SOEs. Besides, they were still allowed to enjoy preferential land rental as well as cheap loans. Unfortunately, business performances of those companies were usually inferior. Some of them even use subsidies to camouflage huge losses and to avoid being an ST company. For example, the China Eastern Airlines made a huge loss in 2008 mainly due to some speculative actions in hedging oil. Yet relied on government subsidies, the company managed to turn this loss into profit in 2009 with insignificant growth regarding business revenues [3]. Despite these loss-making companies, many profitable businesses also seek every opportunity to get a government subsidy. For instance, China National Petroleum Corporation (CNPC) and China Petroleum Chemical Corporation (CPCC), two of the most profitable Chinese SOEs, applied for subsidies to compensate for the loss incurred in oil refining sectors this year. Indeed, CNPC and CPCC had made impressive profits of over 160 billion RMB during the first three quarters. However, both companies had received substantial subsidies in the past several years [17]. In 2005, it was estimated that SOEs' total outputs only accounted for around $1 / 2$ of those of private sector while their total profits well surpassed those of private companies. In contrast with the rapidly declining total number of SOEs over the past decade, their total assets have experienced a sharp increase during the same period of time.

Furthermore, SOEs still gain a monopoly power in a number of key sectors currently, such as telecommunication industry, coal mining industry and oil industry. Although both the old 36-article stipulation and the new 36 had encouraged private entries to various previously inaccessible markets, their broad guidelines resulted in a feasibility problem and the practical enforcement was poor.

\section{Conclusion}

To sum up, China's WTO accession did bring a noticeable impact on the SOE sector. Given the numerous strict WTO provisions, a series of reforms on China's SOEs and essential changes in relevant legislations and government policies were impending. As a consequence, privatization of SOEs as a major reform approach was implemented on a national scale. Among the various methods of privatization, MBO was considered most popular and had most desirable results. Moreover, the privatization process in China has led to a significant development of the private enterprises as well as a reduction in the number of SOEs. However, problems with both the MBO and the privatization process as a whole were also evident. When referring to the legislative and policy-related aspect, the existing law deficiencies and residual subsidies somewhat hindered the reform of SOEs. Therefore, to achieve further development, a more improved legislative system has to be established and a fair environment 
of competition should be ensured. In addition, it was concerned that whether all these transformations were actually the result induced by the WTO accession, or would also have taken place even without the accession. Yet overall, the role of China's WTO accession was undeniably important in stimulating the SOE reform.

\section{References}

[1] Bajona, C. and Chu, T. (2004) China’s WTO Accession and Its Effect on State-Owned Enterprises. East-West Center, Honolulu. http://www.journals.elsevier.com/review-of-economic-dynamics/

[2] World Trade Organization, n.d. Agreement on Subsidies and Countervailing Measures. http://www.wto.org/english/docs_e/legal_e/24-scm_01_e.htm

[3] Lin, J.Y., n.d. WTO Accession and Chinese Economy: Impacts on Agriculture, Financial Sector, and State-Owned Enterprises. http://www.rieti.go.jp/en/events/02042201/lin_1.pdf

[4] Wu, J. (2005) Understanding and Interpreting Chinese Economic Reform. Thomson/South-Western, Mason.

[5] Xue, F. (2011) An Analysis of the Advantages and Disadvantages of MBO to the Enterprises' Development. http://www.chinaacc.com/new/287_296_201103/25wa47653920.shtml

[6] Liu, H.J. (2006) A Review over the Implementation of MBO in China. http://www.lawtime.cn/info/gongsi/gzczmbosg/2006082324949_3.html

[7] Li, X.M. (2003) Analyzing China’s MBO Course through Classical Cases. http://finance.sina.com.cn/roll/20030916/1638447945.shtml

[8] Ji, G.W. (2010) A Study on the Problems of Financing in China's MBO Process. http://www.chinaacc.com/new/287_290_201009/09li2459656700.shtml

[9] Woo, M., n.d. Presentation on Lang Xianping and Debate over MBO (Management Buyout).

[10] Undesirable MBOs for Large SOEs (2004) Available at: http://www.ce.cn/new_hgjj/hgplun/more/200412/15/t20041215_2581925.shtml

[11] Chan, A. and Unger, J. (2009) A Chinese State Enterprise under the Reforms: What Model of Capitalism? Canberra: Contemporary China Center, Australian National University. JSTOR. http://www.jstor.org/stable/20648112

[12] China Eastern Airlines Annual Report (2009). http://www.ceair.com/mu/main/gydh/tzzgx/dqbg/yxglhzqjysfb/2009 1/201004/P020100429340339062760.pdf

[13] Naughton, B. (2007) The Chinese Economy_-Transitions and Growth. The MIT Press, Cambridge.

[14] Tong, S.Y. (2009) Why Privatize or Why Not? Empirical Evidence from China's SOEs Reform.

[15] Megginson, W.L. and Netter, J.M. (2001) From State to Market: A Survey of Empirical Studies on Privatization. American Economic Association, Nashville. http://www.jstor.org/stable/2698243

[16] Wang, C. (2003) Approaching the Deadline: The Ministry of Finance Cleared up SOE Subsidies on a Massive Scale. http://finance.sina.com.cn/g/20030922/0758454483.shtml

[17] Li, C. (2011) Disputes over the Two Most Profitable Oil Enterprises Still Gaining Huge Subsidies. http://finance.qq.com/a/20111129/001123.htm?pgv ref=aio 